\title{
Mandibular Trabecular Structures In Alveolar Ridge Preservation Using Different Grafting Materials After Tooth Extraction
}

\author{
Estructura Trabecular Mandibular en Preservación de Reborde Alveolar \\ Utilizando Diferentes Materiales de Injerto Después de la Exodoncia
}

Mario Cantín ${ }^{1 \dagger}$; Sergio Olate ${ }^{1,2}$ \& Mariano del Sol ${ }^{1}$

CANTIN, M.; OLATE, S. \& DEL SOL, M. Mandibular trabecular structures in alveolar ridge preservation using different materials after tooth extraction. Int. J. Morphol., 36(3):1143-1148, 2018.

SUMMARY: The aim was to describe the star volume analysis in ridge preservation using different grafting materials. Bilateral extraction of the first mandibular molars of sixteen male rabbits was performed, divided at random into four groups ( $\mathrm{n}=4$ in each group) according to graft, using: blood clot (G1), xenograft (G2), pure phase beta-tricalcium phosphate (G3) and biphasic calcium phosphate $(60 \%$ HA / $40 \%$ beta-TCP) (G4). Rabbits were euthanized at 4, 6, or 8 wk post-extraction; the trabecular bone structures was evaluated by star volume analysis. The Levene test was used to analyze variance, as was the independent sample t-test. A P-value of < 0.001 was used to establish a statistically significant. The star volume analysis of the mandibular trabecula shows that the marrow space star volume $\left(V^{*}\right.$ m.space) was higher than the trabecular star volume $\left(V^{*} \operatorname{tr}\right)$. At 6-week post-extraction, new trabecular bone was evident. At 8-week post-extraction $\mathrm{V}^{*} \operatorname{tr}$ increase in all groups and the $\mathrm{V}^{*} \mathrm{~m}$.space diminish, suggesting coarsening of the internal architecture. In G2, some trabecular bone was observed in the central region. In G3, most of the socket regions were occupied by newly formed and loose trabecular bone and in the G4, the sockets were almost entirely filled with trabecular bone. Star volume analysis is adequate to analysis of bone patterns formation using bone substitutes.

KEY WORDS: Extraction socket healing; Bone graft; Socket Preservation.

\section{INTRODUCTION}

Tooth extraction can result in loss of bone volume and remodeling of soft tissues (Araújo et al., 2005; Barone et al., 2015; Cardaropoli \& Cardaropoli, 2008). The socket bone walls will be markedly reduced in height and width (Araújo \& Lindhe, 2005; Araújo et al., 2008; Cardaropoli \& Cardaropoli; Araújo et al., 2009; Poulias et al., 2013). Therefore, following extraction, it would be of interest to arrest or to minimize the bone resorptive process by providing ridge preservation procedures, which should allow treatments associated with more predictable outcomes (Roman et al., 2015), even though the bone modelling and remodelling after a tooth extraction is not completely avoidable (Fickl et al., 2008).

The bone substitutes provide the structural base for new bone, and can function as a spacemaker or scaffold and to maintain the area where new bone is growing. The use of various graft materials has been proposed over the years, such as autogenous bone grafts (Pelegrine et al., 2010), allografts (Wood \& Mealey, 2012), xenografts (Calasans-Maia et al., 2014), and alloplasts (Brkovic et al., 2012) to maintain the dimensions of the alveolar ridge after extraction. It should also be resorbed and eventually fully replaced by bone, ultimately within a well-defined time frame. Although some of these graft materials preserved the post-extraction alveolar ridge dimensions to some extent, the quantity and the quality of the trabecular bone formation in the socket varied (Heberer et al., 2012). Therefore, quantitative assessment of the bone architecture (and its mass and bone quality), which is likely closely related to bone strength is necessary.

Quantitative evaluation of bone is made mainly through bone mineral density measurement, but bone morphological measurements based on biopsy have gained popularity in the quantitative evaluation of trabecular structure as well (Ikuta et al., 2000). Assessment of bone

${ }^{1}$ Program in Morphological Sciences, Centre for Studies in Morphological and Surgical Sciences (CEMyQ), Faculty of Medicine, Universidad de La Frontera, Temuco, Chile.

${ }^{2}$ Division of Oral, Facial and Maxillofacial Surgery, Universidad de La Frontera, Temuco, Chile.

Funded by Universidad de La Frontera, Proyect DI16-0003. 
structure was first performed using direct measurement of trabecular width and spacing (Croucher et al., 1996). Since histomorphometric approaches are primarily based on twodimensional cross-sections, in recent years, the method has been superseded by direct three-dimensional. Star volume analysis was developed as a method of quantifying morphological characteristics of biopsy tissue specimens and precise determination of changes in bone structure, applied directly to bone slices as a method of providing stereological parameters for trabecular changes (Vesterby et al., 1989; Vesterby, 1990; Nakamura et al., 1999).

\section{MATERIAL AND METHOD}

The animal experiments performed in this study were approved by the Institutional Ethic Committee at the Universidad de La Frontera, Protocol No 19/13. Three bone substitutes were used, as follows: one xenograft consisting of deproteinized and lyophilized bovine bone, and two fully alloplastic one based on pure phase beta-tricalcium phosphate (TCP) (>99\%) (alloplastic graft 1) and other based on biphasic calcium phosphate (60\% HA / $40 \%$ beta-TCP) (alloplastic graft 2). In one group (control), extraction socket was filled with a blood clot.

Pre and postoperatively, the animals were kept in individual cages in a temperature-controlled environment with water ad libitum and standardized feed (only preoperatively and five days postoperatively). The animals were anesthetized intramuscularly using $0.1 \mathrm{ml} / 200 \mathrm{~g}$ of animal weight, using equal parts of ketamine and xylazine. A buccal mucoperiosteal flap was raised with a periosteal elevator to expose the extraction socket of first mandibular molar tooth. Bilateral extraction of the first mandibular molars of sixteen male rabbits was performed 21 , divided at random into four groups ( $\mathrm{n}=4$ in each group). Immediately after removing the teeth, the extraction sockets (left and right) were left empty in group 1 (control, no graft treatment), to be filled with blood clot. In groups 2, 3 and 4, the extraction sockets (left and right) were treated with xenograft, alloplastic graft 1 and alloplastic graft 2 , respectively. The flap was sutured with 4-0 polyglyconate in a simple, interrupted pattern.

Oral alimentation was reinitiated 24 hours after surgery with soft food, which was offered during five days. After this period, the animals were fed with commercial rabbit diet. Rabbits were sacrificed at 4,6 , or $8 \mathrm{wk}$ post-extraction for the analysis of the extraction sites.

The jaw segments containing the extraction sockets were removed in block using an electric saw, fixed in $10 \%$ neutral buffered formalin, decalcified in $5 \%$ formic acid, embedded in paraffin, sectioned at five $\mathrm{mm}$ increments, and stained with hematoxylin and eosin. All of the sections were evaluated using a Olympus ${ }^{\circledR}$ CX31 microscope with a Moticam® 480 camera.

Continuity of the trabecular bone structures was evaluated by star volume analysis (Vesterby et al.; Vesterby; Nakamura et al.; Kumasaka et al., 2000; Onoyama et al., 2011). Here, the trabecular bone structure was defined with two measurements: the trabecular star volume $\left(\mathrm{V}^{*} \operatorname{tr}\right)$ and the marrow space star volume $\left(\mathrm{V}^{*} \mathrm{~m}\right.$.space). $\mathrm{V} *$ tr represents the mean volume of a trabecula from a designated internal point in all directions to the margin of the trabecula. $V^{*}$ m.space represents the mean volume of the marrow cavity surveyed from a designated point in all directions without obstruction by the trabecula. With increasing trabecular number and continuity, the $\mathrm{V}^{*}$ tr becomes larger as the $\mathrm{V}^{*} \mathrm{~m}$. space becomes smaller. Conversely, the $\mathrm{V} * \operatorname{tr}$ becomes smaller as the $\mathrm{V} * \mathrm{~m}$.space become larger with decreasing trabecular number and continuity.

A descriptive analysis of the sample subjects was undertaken. The Levene test was used to analyze variance, as was the independent sample t-test. A P-value of $<0.05$ was used to establish a statistically significant relationship.

\section{RESULTS}

The star volume analysis of the mandibular trabecula shows that the $\mathrm{V}^{*} \mathrm{~m}$.space was higher and the $\mathrm{V} *$ tr lower at four-week post-extraction in all groups (Table I). In the control Group, sockets were filled principally with granulation or connective tissues, whereas new bone was almost no visible in the socket. In the xenograft, alloplastic graft 1 and alloplastic graft 2 groups, characteristics that were similar to those of the control group in new bone formation. Some residual alloplastic materials remained in the extraction sockets.

At 6-week post-extraction, new trabecular bone was evident. The $\mathrm{V}^{*} \mathrm{~m}$.space was higher and the $\mathrm{V} * \operatorname{tr}$ lower in control and xenograft groups, but Alloplastic 1 and 2 groups show a higher $\mathrm{V}^{*} \mathrm{tr}$, and reduce its $\mathrm{V}^{*} \mathrm{~m}$.space (Table I).

At 8-week post-extraction $\mathrm{V} *$ tr increase in all groups and the $\mathrm{V}^{*} \mathrm{~m}$.space diminish, suggesting coarsening of the internal architecture (Table I); in all the groups, the 8 wk period showed more quality in new bone formation than the initial 2 or 6 weeks $(\mathrm{p}<0.001)$. In control group a significant amount of newly formed bone was present between the periphery and the central region of the alveolar sockets. In Xenograft group, 
Table I. Star volume analysis after bilateral extraction of the first mandibular molars of sixteen male rabbits, with euthanized at 4,6 and $8 \mathrm{wk}$. Bone formation derived from: A) blood clot, B) deproteinized and lyophilized bovine bone, C) pure phase beta-tricalcium phosphate and D) biphasic calcium phosphate (60\% HA / $40 \%$ beta-TCP).

\begin{tabular}{lrrrrrrr}
\hline Group & \multicolumn{2}{c}{4 week } & \multicolumn{2}{c}{6 week } & \multicolumn{2}{c}{8 week } & P value \\
& $* \operatorname{tr}$ & $*$ m.space & V*tr & $*$ m.space & $* \operatorname{tr}$ & $*$ m.space \\
\hline Control (blood clot) & $0.02 \pm 0.01$ & $0.8 \pm 0.12$ & $0.12 \pm 0.03$ & $0.69 \pm 0.02$ & $0.38 \pm 0.03$ & $0.37 \pm 0.02$ & $0.001 * * *$ \\
Xenograft & $0.01 \pm 0.03$ & $0.8 \pm 0.17$ & $0.14 \pm 0.02$ & $0.67 \pm 0.07$ & $0.39 \pm 0.02$ & $0.35 \pm 0.07$ & $0.001 * * *$ \\
Alloplastic 1 ( $\beta$-TCP) & $07 \pm 0.03$ & $0.8 \pm 0.45$ & $0.42 \pm 0.02$ & $0.38 \pm 0.02$ & $0.56 \pm 0.02$ & $0.28 \pm 0.02$ & $0.001 * * *$ \\
Alloplastic 2 (HA/ $\beta-\mathrm{TCP})$ & $0.22 \pm 0.02$ & $0.8 \pm 0.17$ & $0.52 \pm 0.07$ & $0.27 \pm 0.01$ & $0.69 \pm 0.07$ & $0.12 \pm 0.01$ & $0.001 * * *$ \\
\hline
\end{tabular}

$*=$ Indicate significant differences $\mathrm{P}<0.001$, between $\mathrm{V} * \operatorname{tr}$ among the groups.

$* *=$ Indicate significant differences $\mathrm{P}<0.001$, between $\mathrm{V} * \mathrm{~m}$.space among the groups.

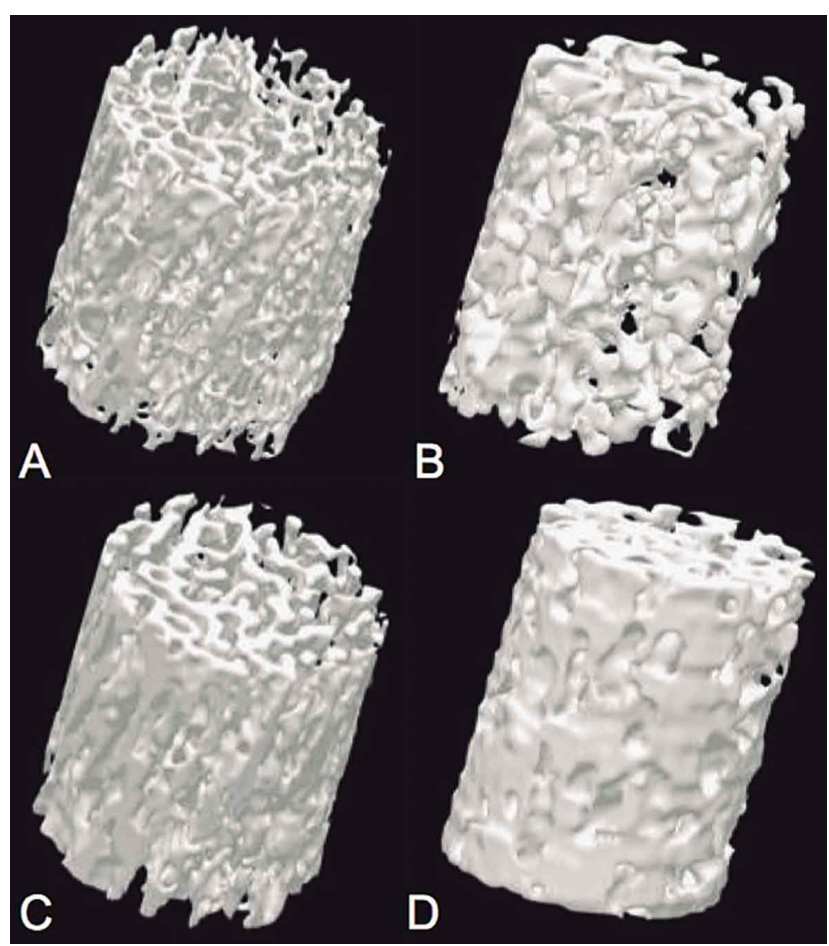

Fig. 1. Three-dimensional reconstruction of the bone trabeculae and their medullary spaces after bilateral extraction of the first mandibular molars of sixteen male rabbits, with euthanized at $8 \mathrm{wk}$. Bone formation derived from: A) Blood clot, B) deproteinized and lyophilized bovine bone, C) pure phase beta-tricalcium phosphate and D) biphasic calcium phosphate (60\% HA / $40 \%$ beta-TCP).

newly formed bone was present principally in the periphery of the alveolar sockets, but some trabecular bone can be see in the central region. In the alloplastic graft 1 group, most of the socket regions were occupied by newly formed and loose trabecular bone; these trabeculae are distributed uniformly in the peripheral and central region of the alveolar sockets. In the alloplastic graft 2 group, the sockets were almost entirely filled with trabecular bone.

A three-dimensional reconstruction of the bone trabeculae and their medullary spaces at 8 weeks, showing the pattern of the new bone formed and its architecture (Fig. 1 ), with clearly differences in the structure.

\section{DISCUSSION}

In this article we introduce a stereological parameter for quantitation of new bone structure -the star volume- which does give an absolute and a reasonably precise estimate of the size of the trabeculae and of the size of the marrow space in three-dimensional terms $\left(\mathrm{mm}^{3}\right.$ or $\mathrm{mm}^{3}$ ), applied to evaluate the new bone formation derived from bone substitutes.

Trabecular bone is a complex quasi-random network of interconnected plates and rods. Trabecular bone constantly remodels through a complex interplay between bone formation by osteoblasts and bone resorption by osteoclasts to adapt dynamically to the stresses to which it is subjected. Plays a crucial role in determining bone strength, and when its structure is anisotropic its loadbearing properties vary with direction as well (Ketcham \& Ryan, 2004). Conventional histomorphometric analysis of bone architecture has the disadvantage that no acceptable methods exist for obtaining totally unbiased stereological estimators from anisotropic tissue without any assumption of the tissue under study (Vesterby et al.).

Various topologic and geometric approaches to characterize bone architecture have been reported in literature (Parfitt et al., 1983; Mellish et al., 1991; Hahn et al., 1992; Stampa et al., 2002; Vasilic et al., 2009). Parfitt et al. conceived a parallel-interconnected plate model of trabecular bone yielding bone area fraction, trabecular bone volume fraction, trabecular bone spacing, and trabecular bone number from two-dimensional histomorphometric sections. Vesterby et al. conceived a new stereological parameter, called star volume, which is the average volume of an object region that can be seen from a point inside that region un-obscured in all directions.

Various bone-grafting materials with different densities are used in ridge preservation procedures. It is hypothesized that bone mineral density of the bone graft 
material used during ridge preservation protocols may influence the overall outcome of the procedure (AlHezaimi et al., 2015).

The histological observations of the present study showed complete bone formation in both experimental and control groups at 8 week, with less bone marrow space. One may consider the marrow space as an aggregate consisting of connected cavities. Increase in the size of this aggregate can be caused by an increase in one or several marrow space cavities. This cavity increase can be due to: a thinning of the separating walls (trabeculae) which will only give a slight increase in the marrow space or b) the increase can be caused by disappearance or perforation of some separating walls with or without changes of the thickness of the walls (trabeculae). A disappearance of some walls - or, equivalently, the appearance of holes in some walls- will on the other hand, give a large increase in the size of the marrow space due to a grater change of measuring very long intercepts without being interrupted by walls (trabeculae). Therefore the five-fold increase we did find in the size of the marrow space can only be explained by disappearance or perforation of some separating walls (trabeculae) due to the bone remodeling process.

The slow resorption or degradation rate of some biomaterials could be considered a clinical advantage to helps in stabilizing the contour, contrary to observed with autogenous bone where a high resorption rate of the original volume was measured (Sbordone et al., 2011). A drawback with calcium phosphate ceramics is that their degradation (and hence their complete replacement with natural bone) often is reduced in vivo. An exception is btricalcium phosphate that has a rapid degradation rate. But the combination between $b$ - tricalcium phosphate and hydroxyapatite with a slow degradation rate, allows a progressive bone sustitution that maintain the bone volume. A systematic review evaluated the effectiveness of bone preservation using graft materials in non-molar alveolar regions and suggested that the graft materials might not prevent physiological resorptive bone processes after tooth extraction, although these materials might reduce changes in the resulting bone dimensions (Ten Heggeler et al., 2011).

The current paradigm recognizes that socket preservation techniques may help in reducing the bone dimensional changes following tooth extraction. Even if complete preservation of ridge dimension after tooth extraction is unlikely to be attainable, there are significant improvements of predictability for future restorative treatments and a decreased need to perform invasive surgical procedures after post-extraction healing (Brownfield \& Weltman, 2012; Roman et al.). The dimensional bone changes occurring after flap and flapless procedures for tooth extraction were reported to be very similar (Araújo \& Lindhe, 2009, 2011), even though contradictory out- comes were observed by other authors (Fickl et al.) who reported differences in the remodeling of the alveolar process after flap or flapless approaches. A recent randomized clinical trial showed that no histological and histomorphometrical differences exist when comparing the flap and the flapless technique for tooth extraction and socket grafting for ridge preservation procedure (Barone et al.).

It is noteworthy that in the present experiment, all walls of the extraction sockets were intact. It is therefore hypothesized that presence of an osseous defect or a pathological lesion within or around the extraction socket may jeopardize new bone formation.

It may be possible that $\mathrm{V}^{*} \operatorname{tr}$ can serve as an indicator not only for the amount of bone elements but also for structural characteristics such as continuity; this could relate to the fact that the formulas of star volume analysis used for quantitative analysis of bone sections were directly to the quantitative analysis of histological section. Star volume analysis estimates each marrow cavity space as a sphere, and thus the Vm space is based on the formulas used to calculate spherical volumes. However, the $\mathrm{Vm}$ on histological section images does not have a spherical shape (Ikuta et al.).

In conclusion, this result suggests the potential for using star volume analysis for quantitative analysis of bone patterns formation using bone substitutes, or its evaluation under metabolic diseases that can affect the bone, and also may be useful in detecting differences in skeletal structure, parameters of interest in implant dentistry or maxillofacial surgery fields. We have introduced a stereological parameter to analyze the new bone formation, wich provides an unbiased estimate of a size characterizing the marrow space and the trabeculae of new bone formed from different types of grafts, used for alveolar ridge preservation techniques (socket grafting) following tooth extraction procedures.

\section{ACKNOWLEDGMENT}

The authors want to would thank to the Dirección de Investigación, Universidad de La Frontera by the financial support in this research (DI16-0003). 
CANTIN, M.; OLATE, S. \& DEL SOL, M. Estructura trabecular mandibular en preservación del reborde alveolar utilizando diferentes materiales de injerto después de la exodoncia. Int. J. Morphol., 36(3):1143-1148, 2018.

RESUMEN: El objetivo de esta investigación fue describir el volumen estrella en preservación alveolar utilizando diferentes injertos óseos. La exodoncia bilateral del primer molar mandibular de 16 conejos machos fue realizada, dividiéndolos en 4 grupos ( $\mathrm{n}=4$ en cada grupo) de acuerdo al injerto utilizado, siendo: coágulo sanguíneo $(\mathrm{G} 1)$, xenoinjerto $(\mathrm{G} 2)$, beta-tricalcio fosfato puro (G3) y fosfato de calcio bifásico $(60 \%$ HA / $40 \%$ beta-TCP) (G4). Los conejos fueron sometidos a eutanasia a las 4,6 u 8 semanas post exodoncia; el trabeculado óseo fue evaluado por medio del volumen estrella. La prueba de Levene fue utilizado para el análisis de varianza y luego la prueba t-test para muestras independientes. El valor de $\mathrm{P}$ menor a 0.001 fue establecido como significancia estadística. El análisis del volumen estrella del trabeculado mostró que el espacio medular de volumen estrella $(\mathrm{V} * \mathrm{~m}$.space) fue mayor que trabeculado ( $\mathrm{V} * \mathrm{tr})$. A 6 semanas post exodoncia, nuevo trabeculado óseo fue evidente. A las 8 semanas post exodoncia $\mathrm{V} *$ tr aumenta en todos los grupos y el $\mathrm{V} *$ m.space disminuye, sugiriendo un engrosamiento de la arquitectura interna. En el grupo G2, algún trabeculado óseo fue observado en la región central. En el G3, la mayoría del alveolo fue ocupado por nuevo hueso y perdió trabeculado óseo y en G4, el alveolo fue ocupado casi enteramente por hueso trabecular. El análisis de volumen estrella es adecuado para analizar el modelo de formación ósea utilizando sustitutos óseos.

PALABRAS CLAVE: Reparación alveolo post extracción; Injerto óseo; Preservación alveolar.

\section{REFERENCES}

Al-Hezaimi, K.; Iezzi, G.; Rudek, I.; Al-Daafas, A.; Al-Hamdan, K.; AlRasheed, A.; Javed, F.; Piattelli, A. \& Wang, H. L. Histomorphometric analysis of bone regeneration using a dual layer of membranes (dPTFE placed over collagen) in fresh extraction sites: a canine model. J. Oral Implantol., 41(2):188-95, 2015.

Araújo, M. G. \& Lindhe, J. Dimensional ridge alterations following tooth extraction. An experimental study in the dog. J. Clin. Periodontol., 32(2):212-8, 2005.

Araújo, M. G. \& Lindhe, J. Ridge alterations following tooth extraction with and without flap elevation: an experimental study in the dog. Clin. Oral Implants Res., 20(6):545-9, 2009.

Araújo, M. G. \& Lindhe, J. Socket grafting with the use of autologous bone: an experimental study in the dog. Clin. Oral Implants Res., 22(1):9-13, 2011

Araújo, M. G.; Sukekava, F.; Wennström, J. L. \& Lindhe, J. Ridge alterations following implant placement in fresh extraction sockets: an experimental study in the dog. J. Clin. Periodontol., 32(6):645-52, 2005.

Araújo, M.; Linder, E.; Wennström, J. \& Lindhe, J. The influence of BioOss Collagen on healing of an extraction socket: an experimental study in the dog. Int. J. Periodontics Restorative Dent., 28(2):123-35, 2008.

Barone, A.; Borgia, V.; Covani, U.; Ricci, M.; Piattelli, A. \& Iezzi, G. Flap versus flapless procedure for ridge preservation in alveolar extraction sockets: a histological evaluation in a randomized clinical trial. Clin. Oral Implants Res., 26(7):806-13, 2015.
Brkovic, B. M.; Prasad, H. S.; Rohrer, M. D.; Konandreas, G.; Agrogiannis, G.; Antunovic, D. \& Sándor, G. K. Beta-tricalcium phosphate/type I collagen cones with or without a barrier membrane in human extraction socket healing: clinical, histologic, histomorphometric, and immunohistochemical evaluation. Clin. Oral Investig., 16(2):581-90, 2012.

Brownfield, L. A \& Weltman, R. L. Ridge preservation with or without an osteoinductive allograft: a clinical, radiographic, micro-computed tomography, and histologic study evaluating dimensional changes and new bone formation of the alveolar ridge. J. Periodontol., 83(5):581-9, 2012.

Calasans-Maia, M.; Resende, R.; Fernandes, G.; Calasans-Maia, J.; Alves, A. T. \& Granjeiro, J. M. A randomized controlled clinical trial to evaluate a new xenograft for alveolar socket preservation. Clin. Oral Implants Res., 25(10):1125-30, 2014.

Cardaropoli, D. \& Cardaropoli, G. Preservation of the postextraction alveolar ridge: a clinical and histologic study. Int. J. Periodontics Restorative Dent., 28(5):469-77, 2008.

Croucher, P. I.; Garrahan, N. J. \& Compston, J. E. Assessment of cancellous bone structure: comparison of strut analysis, trabecular bone pattern factor, and marrow space star volume. J. Bone Miner. Res., 11(7):955-61, 1996.

Fickl, S.; Zuhr, O.; Wachtel, H.; Stappert, C. F.; Stein, J. M. \& Hürzeler, M. B. Dimensional changes of the alveolar ridge contour after different socket preservation techniques. J. Clin. Periodontol., 35(10):906-13, 2008.

Hahn, M.; Vogel, M.; Pompesius-Kempa, M. \& Delling, G. Trabecular bone pattern factor--a new parameter for simple quantification of bone microarchitecture. Bone, 13(4):327-30, 1992.

Heberer, S.; Wustlich, A.; Lage, H.; Nelson, J. J. \& Nelson, K. Osteogenic potential of mesenchymal cells embedded in the provisional matrix after a 6-week healing period in augmented and non-augmented extraction sockets: an immunohistochemical prospective pilot study in humans. Clin. Oral Implants Res., 23(1):19-27, 2012.

Ikuta, A.; Kumasaka, S. \& Kashima, I. Quantitative analysis using the star volume method applied to skeleton patterns extracted with a morphological filter. J. Bone Miner. Metab., 18(5):271-7, 2000.

Ketcham, R. A. \& Ryan, T. M. Quantification and visualization of anisotropy in trabecular bone. J. Microsc., 213(Pt. 2):158-71, 2004.

Kumasaka, S.; Kiyohara, S.; Takahashi, T.; Asai, H. \& Kashima, I. Morphologically extracted trabecular skeleton superimposed upon digital radiograph structure. J. Bone Miner. Metab., 18(4):208-11, 2000.

Mellish, R. W.; Ferguson-Pell, M. W.; Cochran, G. V.; Lindsay, R. \& Dempster, D. W. A new manual method for assessing two-dimensional cancellous bone structure: comparison between iliac crest and lumbar vertebra. J. Bone Miner. Res., 6(7):689-96, 1991.

Nakamura, K.; Matsubara, M.; Asai, H.; Koyama, A.; Fujikawa, T. \& Kashima, I. Mathematical morphology for extraction of bone trabecular pattern: preliminary investigation of quantitative analysis using the star volume. J. Jpn. Soc. Bone Morphom., 9:45-51, 1999.

Onoyama, K.; Kawamata, R.; Kozai, Y.; Sakurai, T. \& Kashima, I. Comparison of mandibular trabecular structures between normal and diabetic rats: evaluation of spontaneous type 2 diabetes in a rat model. Oral Radiol., 27:35, 2011.

Parfitt, A. M.; Mathews, C. H.; Villanueva, A. R.; Kleerekoper, M.; Frame, B. \& Rao, D. S. Relationships between surface, volume, and thickness of iliac trabecular bone in aging and in osteoporosis. Implications for the microanatomic and cellular mechanisms of bone loss. J. Clin. Invest., 72(4):1396-409, 1983.

Pelegrine, A. A.; da Costa, C. E.; Correa, M. E. \& Marques, J. F. Jr. Clinical and histomorphometric evaluation of extraction sockets treated with an autologous bone marrow graft. Clin. Oral Implants Res., 21(5):53542, 2010.

Poulias, E.; Greenwell, H.; Hill, M.; Morton, D.; Vidal, R.; Shumway, B. \& Peterson, T. L. Ridge preservation comparing socket allograft alone to socket allograft plus facial overlay xenograft: a clinical and histologic study in humans. J. Periodontol., 84(11):1567-75, 2013. 
Roman, A.; Cioban, C.; Stratul, S. I.; Schwarz, F.; Muste, A.; Petrutiu, S. A.; Zaganescu, R. \& Mihatovic, I. Ridge preservation using a new 3D collagen matrix: a preclinical study. Clin. Oral Investig., 19(6):152736,2015

Sbordone, C.; Sbordone, L.; Toti, P.; Martuscelli, R.; Califano, L. \& Guidetti, F. Volume changes of grafted autogenous bone in sinus augmentation procedure. J. Oral Maxillofac. Surg., 69(6):1633-41, 2011.

Stampa, B.; Kuhn, B.; Liess, C.; Heller, M. \& Glüer, C. C. Characterization of the integrity of three-dimensional trabecular bone microstructure by connectivity and shape analysis using high-resolution magnetic resonance imaging in vivo. Top. Magn. Reson. Imaging, 13(5):357-63, 2002.

Ten Heggeler, J. M.; Slot, D. E. \& Van der Weijden, G. A. Effect of socket preservation therapies following tooth extraction in non-molar regions in humans: a systematic review. Clin. Oral Implants Res., 22(8):77988, 2011.

Vasilic, B.; Rajapakse, C. S. \& Wehrli, F. W. Classification of trabeculae into three-dimensional rodlike and platelike structures via local inertial anisotropy. Med. Phys., 36(7):3280-91, 2009.

Vesterby, A. Star volume of marrow space and trabeculae in iliac crest: sampling procedure and correlation to star volume of first lumbar vertebra. Bone, 11(3):149-55, 1990.

Vesterby, A.; Gundersen, H. J. \& Melsen, F. Star volume of marrow space and trabeculae of the first lumbar vertebra: sampling efficiency and biological variation. Bone, 10(1):7-13, 1989.

Wood, R. A. \& Mealey, B. L. Histologic comparison of healing after tooth extraction with ridge preservation using mineralized versus demineralized freeze-dried bone allograft. J. Periodontol., 83(3):32936, 2012.

\author{
Dirección para correspondencia: \\ Sergio Olate \\ Departamento de Odontología Integral Adultos \\ Facultad de Odontología \\ Universidad de La Frontera \\ Temuco \\ CHILE
}

Email: sergio.olate@ufrontera.cl

Recibido : 04-03-2018

Aceptado: 16-06-2018 